\title{
Analysis of patient-specific immunoglobulin proteomes and transcriptomes by PCR cloning and mass spectrometry
}

\section{Birgit Obermeier}

Institute of Clinical Neuroimmunology, Ludwig Maximilians University, D-81377 Munich, Germany; and: Department of Neuroimmunology, Max-Planck-Institute of Neurobiology, D-82152 Martinsried, Germany

\section{Reinhard Mentele}

Department for Protein Analytics, Max-Planck-Institute of Biochemistry, D-82152 Martinsried, Germany

\section{Joachim Malotka}

Department of Neuroimmunology, Max-Planck-Institute of Neurobiology, D-82152 Martinsried, Germany

\section{Klaus Dornmair}

Institute of Clinical Neuroimmunology, Ludwig Maximilians University, D-81377 Munich, Germany; and: Department of Neuroimmunology, Max-Planck-Institute of Neurobiology, D-82152 Martinsried, Germany

\section{Method Article}

Keywords: autoimmunity, multiple sclerosis, oligoclonal bands, immunoglobulin, VDJ recombination, somatic hypermutation, mass spectrometry, proteomics, transcriptomics

Posted Date: May 21st, 2008

DOI: https://doi.org/10.1038/nprot.2008.87

License: (c) (i) This work is licensed under a Creative Commons Attribution 4.0 International License. Read Full License 


\section{Abstract}

\section{Introduction}

We describe a method for relating oligoclonally expanded B cells at particular body locations to their secreted products, soluble immunoglobulins. The technique makes use of the virtually infinite variability of mature immunoglobulin $\backslash(\mathrm{lg})$ chains, which results from VDJ recombination and somatic hypermutation $\backslash(\mathrm{SHM})$. We create patient-specific transcriptome databases by PCR-cloning of Ig transcripts of B cells from the relevant location. In parallel, we analyze the Ig proteome at the location of interest. To this end, we isolate the Ig molecules by affinity chromatography and isoelectric focusing, and analyze them by trypsin digestion and subsequent mass spectrometry. Then the patient-specific Ig proteomes and transcriptomes are compared by searching for the peptides identified by mass spectrometry in the transcriptome databases. We place particular focus on the peptides that carry characteristic amino acids introduced by VDJ recombination and SHM. Specific matches suggest that the particular B cells produce the oligoclonally expanded antibodies. We applied the method to cerebrospinal fluid from multiple sclerosis patients. However, the technique will also be applicable to antibody populations that are expanded in body fluids or tissues of any species.

\section{Reagents}

**Ig mRNA cloning and analysis:** - RNeasy Micro Kit $\backslash\left(\right.$ Qiagen) - the RT reaction mix is described ${ }^{1}$. It containes $0.5 \%$ IGEPAL CA-630 \(Sigma), $5 \mu \mathrm{M}$ Random Primer \(Invitrogen), $0.25 \mathrm{mM}$ dNTP \ (Invitrogen), $10 \mathrm{mM}$ DTT \(Fluka), 0.33 Units/ $\mu$ l Prime RNase InhibitorTM \(Eppendorf), 0.6 Units/ $\mu$ l, RNasin ${ }^{\circledR}$ Plus RNase Inhibitor \(Promega), 2.5 Units/ $\mu$ l SuperScriptTMIII Reverse Transcriptase \ (Invitrogen). In addition we added $0.25 \mu \mathrm{M}$ Primer HG-RT $1^{2}$. - PCR reaction mixes: all reaction mixes contained $0.2 \mathrm{mM}$ dNTP, 0.05 Units/ $\mu$ I Taq Polymerase $\backslash$ (Roche). We use specific primer pools for IgG-H, Ig-K, and Ig- $\lambda$ chains. PCR amplification is performed as nested PCR with outer and inner primer pools. Each primer pool is used at $0.5 \mu \mathrm{M}$. All forward and reverse primers are described ${ }^{1,2}$. In addition we added a specific inner forward primer for VH1: Age1 VH1: 5'-

CTGCAACCGGTGTACATTCCCAGGTGCAGCTGGTGCAG-3'. The outer forward primers for the first round of

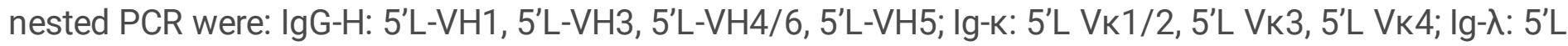
$\mathrm{V} \lambda 1,5^{\prime} \mathrm{L} V \lambda 2,5^{\prime} \mathrm{L} V \lambda 3,5^{\prime} \mathrm{L} V \lambda 4 / 5,5^{\prime} \mathrm{L} V \lambda 6,5^{\prime} \mathrm{L} V \lambda 7,5^{\prime} \mathrm{L} V \lambda 8$. The inner forward primers for the second round of nested PCR were: IgG-H: 5’Age1 VH1, 5’Agel VH1/5, 5’Agel VH3, 5’Agel VH4; ; Ig-к: 5’Pan Vк; Ig- $\lambda$ : $5^{\prime}$ Agel $V \lambda 1,5^{\prime}$ Agel $V \lambda 2,5^{\prime}$ Agel $V \lambda 3,5^{\prime}$ Agel $V \lambda 4 / 5,5^{\prime}$ Agel $V \lambda 6,5$ 'Agel $V \lambda 7 / 8$. The outer reverse primers for the first round of nested PCR were: IgG-H: HG-CH1-aa35-43-rev-out-2 Ig-K: C-Kap-aa17-23-rev-out Ig- $\lambda$ : CLam-aa16-22-rev-out The inner reverse primers for the second round of nested PCR were: IgG-H: HG-CH1aa22-29-rev-in Ig-K: C-Kap-aa1-7-rev-in Ig- $\lambda$ : C-Lam-aa10-16-rev-in1 - Agarose \(Biozym) - TBE buffer \ (10x): $0.89 \mathrm{M}$ Tris $\backslash($ Sigma), $0.89 \mathrm{M}$ Borat $\backslash($ Merck), $0.02 \mathrm{M}$ EDTA $\backslash($ Merck), pH 8.0 - Ethidiumbromide $\backslash$ (Sigma) - DNA sample buffer \(6x): 50\% Glycerol \(Merck), 0.02\% Bromphenol blue \(Sigma); 0.02\% Xylencyanol FF \(BioRad), 10 mM Tris, pH 7.5 - 100 bp DNA Ladder $\backslash\left(N e w\right.$ England Biolabs) - Easypure ${ }^{\circledR}$ 
DNA Purification Kit \(Biozym) - EB buffer \(Qiagen) - TOPO-TA cloning Kit \(Invitrogen) - LB medium: 10 g BactoTM Trypton \(Becton Dickinson), $5 \mathrm{~g}$ BactoTM Yeast Extract $\backslash($ Becton Dickinson), $10 \mathrm{~g} \mathrm{NaCl} \backslash$ (Merck), ad 1 I H2O; for Agar add 1.5\% BactoTM Agar \(Becton Dickinson) - Ampicillin \(Sigma) - QIAprep Spin Miniprep Kit $\backslash($ Qiagen) All aqueous solutions were prepared from DEPC treated water. **Ig Protein purification and mass spectrometry** - Dynabeads ${ }^{\circledR}$ Protein $\mathrm{G} \backslash($ Invitrogen) - Washing buffer for Dynabeads ${ }^{\circledR}$ Protein G: $0.1 \mathrm{M} \mathrm{Na}$-acetate $\backslash($ Merck), $0.15 \mathrm{M} \mathrm{NaCl}, \mathrm{pH} 5.0$ - Elution buffer for Dynabeads $\circledast$ Protein G: 6 M Urea \(Sigma), 2 M Thiourea \(Sigma), 4\% CHAPS \(Sigma), $40 \mathrm{mM}$ Tris base $\backslash($ Sigma), Bromphenol blue - RH buffer: $8 \mathrm{M}$ Urea, $2 \mathrm{M}$ Thiourea, 2\% CHAPS, 2\% SERVALYT 3-10 \(SERVA Electrophoresis), Bromphenol blue - $24 \mathrm{~cm}$ Immobiline DryStrip pH 3-10 \(GE Healthcare) - Kerosene pure $\backslash($ SERVA electrophoresis) - Silicone DC 200 fluid \(SERVA electrophoresis) - TCA \(Riedel-de Haën) Roti ${ }^{\circledR}-B l u e ~ \($ Roth) - Buffer for Trypsin digestion: $10 \mathrm{mM} \mathrm{NH4HCO3} \backslash$ (Sigma) pH=8.5 - DTT \(Merck) Acetonitrile $\backslash($ Merck) - Jodoacetamide $\backslash($ Sigma) - Trypsin $\backslash$ (Roche) - a-cyano-4-hydroxy cinnamic acid $\backslash$ (Sigma) - ProteoMass Peptide MALDI-MS Calibration Kit \(Sigma): MS-CAL2

\section{Equipment}

- Megafuge 1.0.R \(Heraeus Instruments) - Tabletop Microcentrifuge \(Eppendorf) - Thermocycler $\backslash$ (Biometra) - GeneAmp PCR System 9600 Thermocycler \(Perkin Elmer) - Power Supply EPS 500/400 \ (Amersham Pharmacia) - Thermomixer Comfort $5436 \backslash$ (Eppendorf) - Incubator HT \(Infors) - Magnet Dynal MPC@-S \(Invitrogen) - LKB 2117 Multiphor II Electrophoresis System and corresponding equipment \(Amersham Pharmacia) - MultiTempTM III Thermostatic Circulator \(Amersham Pharmacia) Power Supply EPS 3501 XL \(Amersham Pharmacia) - Power Supply LKB 2297 Macrodrive \(Amersham Pharmacia) - Shaker SM-30 CONTROL \(Edmund Bühler) - MALDI Steel Target $\backslash$ (Bruker Daltonic) - Bruker Ultraflex II TOF TOF Spectrometer \(Bruker Daltonic) - Proteomics Analyzer 4700 Spectrometer $\backslash$ (Applied Biosystems) - Software" Flex Control" \(Bruker Daltonic) - Software "Flex Analysis" \(Bruker Daltonic) Program "Mascot Peptide Mass Fingerprint $\backslash($ Matrix Science) - Program "Mascot MS/MS Ions Search" $\backslash$ (Matrix Science)

\section{Procedure}

${ }^{* * A}$ ) Clinical samples** 1) Centrifuge $3 \mathrm{ml}$ fresh CSF sample from lumbar puncture at 1,750 $\mathrm{g}$ for $10 \mathrm{~min}$ at $4{ }^{\circ} \mathrm{C}$. 2) Freeze supernatant immediately at $-80^{\circ} \mathrm{C}$. 3) Lyse cells in $350 \mu \mathrm{RLT}$ buffer and store until further processing at $-80^{\circ} \mathrm{C}$. ${ }^{*} \mathrm{~B}$ ) Analysis of IgG transcripts ${ }^{\star \star} 4$ ) Isolate RNA using the RNeasy Micro Kit according to the recommendations of the manufacturer. Add $5 \mu$ of carrier poly-A-RNA $\backslash(4 \mathrm{ng} / \mu \mathrm{l})$ to cell lysate if fewer than 5,000 cells are analyzed. 5) Elute RNA in $14 \mu \mathrm{l}$ RNase-free water; final volume results in $12 \mu \mathrm{l}$. 6) Perform reverse transcription in $20 \mu \mathrm{l}$ final volume RT reaction mix for $90 \mathrm{~min}$ at $37^{\circ} \mathrm{C}^{1}$. Use the total amount of RNA from step 5. 7) Amplify IgG Heavy and Light chain cDNAs in independent experiments. Each experiment contains two rounds of nested PCR in final volumes of $20 \mu \mathrm{l}$. Use forward outer and inner primers ${ }^{1}$, and reverse outer and inner primers ${ }^{2}$ as described. Use $3 \mu$ of cDNA as template for the first, outer PCRs and $2 \mu$ of PCR product of the first reaction as template for the second, inner 
PCR. The reaction conditions are: First PCR: $3 \min 94^{\circ} \mathrm{C}$; 50 cylces of $30 \sec 94^{\circ} \mathrm{C}, 30 \sec 55^{\circ} \mathrm{C}, 55 \mathrm{sec}$ $72{ }^{\circ} \mathrm{C} ; 10$ min $72{ }^{\circ} \mathrm{C}$; Second PCR: 3 min $94^{\circ} \mathrm{C}$; 50 cylces of $30 \sec 94^{\circ} \mathrm{C}, 30 \sec 55^{\circ} \mathrm{C}, 45 \sec 72{ }^{\circ} \mathrm{C} ; 10$ min $72{ }^{\circ} \mathrm{C}$. 8) Separate PCR products by electrophoresis in $2 \%$ agarose/TBE buffer. 9) Isolate IgG Heavy and Light chains using the Easypure ${ }^{\circledR}$ DNA Purification Kit according to the recommendations of the manufacturer. Dissolve purified DNA in $12 \mu \mathrm{lEB}$ buffer. 10) Insert the IgG heavy and light chains into the pCR $\circledast 2.1 T O P O$ vector using the TOPO TA Cloning Kit, transform One Shot ${ }^{\circledR}$ Chemically Competent E.coli, and select by blue/white screening according to the recommendations of the manufacturer. Pick at least 40 white colonies per chain for further analysis and culture them overnight in $3 \mathrm{ml}$ LB medium containing $100 \mu \mathrm{g} / \mu \mathrm{l}$ ampicillin. 11) Isolate plasmid DNA using QIAprep Spin Miniprep Kit. Elute plasmid DNA in 30 $\mu \mathrm{l}$ EB buffer. 12) Perform DNA sequencing by standard methods using the primer "M13 forward $\backslash(-20) " \backslash$ (Invitrogen). 13) Analyze lgG Heavy and Light chains. The germline sequences are available at "http://vbase.mrc-cpe.cam.ac.uk":http://vbase.mrc-cpe.cam.ac.uk \(MRC Centre for Protein Engineering). 14) Convert sequences in FASTA format. They can then be entered into the mass spectrometry data analysis program "MASCOT Peptide Mass Fingerprint" $\backslash\left(\right.$ Matrix Science). ${ }^{* *} \mathrm{C}$ ) Analysis of IgG proteins ${ }^{\star \star}$ _Protein $\mathrm{G}$ affinity chromatography_ 15) Wash Dynabeads ${ }^{\circledR}$ Protein $\mathrm{G}$ three times in $0.1 \mathrm{M}$ Na-acetate, $0.15 \mathrm{M} \mathrm{NaCl} \mathrm{pH} \mathrm{5.0.16)} \mathrm{Centrifuge} \mathrm{CSF} \mathrm{supernatant} \mathrm{at} 17,500 \mathrm{~g}$ for $5 \mathrm{~min}$ at $4{ }^{\circ} \mathrm{C} \backslash$ (Microcentrifuge 5417 R) 17) Add $200 \mu$ l of Dynabeads ${ }^{\circledR}$ Protein $G$ bead suspension to CSF supernatant. Typically, we used 50 to $200 \mu \mathrm{g} \mathrm{IgG}$ in 1 to $2 \mathrm{ml} \mathrm{CSF}$ supernatant. 18) Shake at $300 \mathrm{rpm}$ for $60 \mathrm{~min}$ at room temperature on a thermomixer. We used $2 \mathrm{ml}$ low binding polypropylene reaction vessels $\backslash$ (Biozym) to prevent protein adsorption and allow efficient mixing. 19) Wash Dynabeads ${ }^{\circledR}$ Protein $\mathrm{G}$ three times in $0.1 \mathrm{M} \mathrm{Na}$ acetate/0.15 M NaCl pH 5.0. 20) Elute IgG in $50 \mu$ Urea-containing Elution buffer; Repeat elution so that the final volume is $100 \mu \mathrm{l}$. _Isoelectric focusing_ 21) Rehydrate $24 \mathrm{~cm}$ Immobiline DryStrip pH 3-10 in RH buffer overnight at room temperature according to the recommendations of the manufacturer. 22) Load the sample directly at the cathodic end $\backslash(\mathrm{pH}=10)$ onto rehydrated Immobiline DryStrip using the Multiphor II Electrophoresis System. 23) Perform isoelectric focusing. The voltage is increased in consecutive steps: $300 \mathrm{~V}$ for $1 \mathrm{~h}, 600 \mathrm{~V}$ for $15 \mathrm{~min}, 900 \mathrm{~V}$ for $15 \mathrm{~min}, 1200 \mathrm{~V}$ for $15 \mathrm{~min}, 1500 \mathrm{~V}$ for $15 \mathrm{~min}, 1800 \mathrm{~V}$ for 15 min, $2100 \mathrm{~V}$ for $15 \mathrm{~min}, 2500 \mathrm{~V}$ for $15 \mathrm{~min}, 3000 \mathrm{~V}$ for $15 \mathrm{~min}, 3500 \mathrm{~V}$ for $15 \mathrm{~min}, 4000 \mathrm{~V}$ for $15 \mathrm{~min}, 4500$ $\mathrm{V}$ for $15 \mathrm{~min}, 5000 \mathrm{~V}$ for $20 \mathrm{~h}$. 24) Fix proteins for $30 \mathrm{~min}$ in 12\% TCA at room temperature on a slow shaker. 25) Wash IPG strip for 3 min in $25 \%$ methanol. 26) Stain IPG strip for $2 \mathrm{~h}$ by colloidal Roti®-Blue at room temperature on a slow shaker. 27) Destain overnight in $30 \%$ methanol/10\% acetic acid. _In-gel digestion by Trypsin ${ }^{3}{ }_{2} 28$ ) Excise appropriate bands and transfer separately to reaction tubes. 29) Add 20-50 $\mu \mathrm{l}$ of $10 \mathrm{mM} \mathrm{NH} 4 \mathrm{HCO} 3$ to each tube so that the gel slice is completely covered. Incubate for $5 \mathrm{~min}$ at room temperature. 30) Discard supernatant and wash the piece of gel with 20-50 $\mu 100 \%$ acetonitrile. 31) Repeat steps 29 and 30. 32) Reduce IgG disulfide bonds by adding 20-50 $\mu$ of $10 \mathrm{mM}$ DTT in $10 \mathrm{mM}$ $\mathrm{NH} 4 \mathrm{HCO} 3$. Incubate for $30 \mathrm{~min}$ at $60^{\circ} \mathrm{C}$. Discard supernatant. 33) Wash twice with $100 \%$ acetonitrile. 34) Alkylate cysteins by adding 20-50 $\mu \mathrm{l}$ of $50 \mathrm{mM}$ jodoacetamide in $10 \mathrm{mM} \mathrm{NH} 4 \mathrm{HCO}$. Incubate for $15 \mathrm{~min}$ at room temperature. Discard supernatant. 35) Wash with 100\% acetonitrile. 36) Wash with $10 \mathrm{mM}$ $\mathrm{NH} 4 \mathrm{HCO} 3$ and discard supernatant. 37) Wash with $100 \%$ acetonitrile. 38) Wash with $10 \mathrm{mM} \mathrm{NH} 4 \mathrm{HCO} 3$ and discard supernatant. 39) Wash twice with $100 \%$ acetonitrile. 40) Digest IgG by $0.1 \mu \mathrm{g}$ Trypsin in 2050 pl 10 mM NH4HCO3. Incubate overnight at $37^{\circ} \mathrm{C}$. _MALDI-TOF_ 41) Prepare MALDI-MS matrix: mix 
10mM NH4H2P04/50\% acetonitrile/0.1\% TFA with a-cyano-4-hydroxycinnamic acid in 50\% acetonitrile/ $0.1 \%$ TFA. 42) Mix $1 \mu \mathrm{l}$ of MALDI-MS matrix with $1 \mu \mathrm{l}$ of sample and spot onto a well of the MALDI Steel Target. Dry at room temperature. 43) Mix $1 \mu \mathrm{l}$ of MALDI-MS matrix with $1 \mu \mathrm{l} \mathrm{MS-CAL2} \mathrm{and} \mathrm{spot} \mathrm{onto}$ another MALDI Steel Target well. Dry at room temperature. 44) Insert the MALDI Steel Target in Bruker Ultraflex II TOF TOF Spectrometer. 45) Operate Mass Calibration according to the recommendations of the manufacturer. 46) Measure samples for Mass Fingerprint in the "Proteomics method" mode. Use 250-1000 shots, Laser Power 20-40\%, accelerating voltage 20kV, Reflector Voltage 22.8KV, 1700-1750V Reflector Detector Voltage. 47) Save and analyze MS spectra by software "Flex Analysis", S/N \(signal to noise percentage): 1-4\%. 48) Copy peaklist in program "Mascot Peptide Mass Fingerprint". 49) Use the following parameters for Mascot Search: Enzyme: Trypsin Allowed missed cleavages: 1 Fixed modification: Carbamidomethyl $\backslash(\mathrm{C})$ Variable modifications: Oxidation $\backslash(\mathrm{M}), \backslash(\mathrm{W})$ Peptide tolerance: +/100 ppm Mass values: MH+ Monoisotopic Report top: 100 hits 50) For MS/MS analysis use "LIFT method" mode. Use 250-1000 shots, Laser Power 50-90\%, accelerating voltage 20kV, 1700-1750V Reflector Detector Voltage. 51) Save and analyze MS/MS spectra by software "Flex Analysis", S/N \ (signal to noise percentage): 1-4\%. 52) Copy peaklist in program "Mascot MS/MS Ions Search". 53) Use the following parameters for Mascot Search: Enzyme: Trypsin Allowed missed cleavages: 1 Fixed modification: Carbamidomethyl $\backslash(\mathrm{C})$ Variable modifications: Oxidation $\backslash(\mathrm{M}), \backslash(\mathrm{W})$ Peptide tolerance: $+/-$ 100 ppm Peptide charge: 1+ Data format: Bruker $\backslash($ xml) Instrument: MALDI TOF TOF MS/MS tol: +/- 0.8 Da Monoisotopic Precursor: mass of interest Report top: 100 hits

\section{Critical Steps}

1) We have investigated cerebrospinal fluid from multiple sclerosis patients which contained 7,000 to $20,000 \mathrm{cells} / \mathrm{ml}$ and $>50 \mu \mathrm{g} \mathrm{gG} / \mathrm{ml}$. If other samples will be investigated, the sample preparations may need to be modified. 4) The samples must contain oligoclonally expanded B cell populations. If polyclonal B cells are investigated, some Ig transcripts will be detected at random $\backslash$ (note that the total Ig repertoire exceeds $10^{9}$ different Ig species per individual). 21) The samples must contain oligoclonal Ig molecules. In a polyclonal population, the concentration of each individual Ig species may be too low to be detected by isoelectric focusing and mass spectrometry.

\section{Troubleshooting}

No PCR products obtained: Check RNA quality of your samples on a Agilent Bioanalyzer. Test or establish the method using fresh peripheral blood mononuclear cells from blood, isolated B-cells, or B-hybridoma cell lines. No bands on IEF gels: a) the binding strength of protein $G$ to different Ig subtypes differs and is species dependent. Make sure that the subtype you are interested in may be purified by protein $\mathrm{G}$. Check elution from protein $\mathrm{G}$ dynabeads. b) the amount of Ig needs to be sufficient for detection by Coomassie $\backslash$ (Roti-Blue). c) there are no olgiclonal Ig molecules in the preparation. Polyclonal Ig molecules give a broad smear on IEF gels. 


\section{References}

1. Wardemann,H._et al_. Predominant autoantibody production by early human B cell precursors. _Science_ ${ }^{* * 301 * \star}, 1374-1377 \backslash(2003)$ 2. Obermeier,B._et al_. Matching of oligoclonal Ig transcriptomes and proteomes of cerebrospinal fluid in multiple sclerosis. _Nat. Med_. in press. 3. Shevchenko,A., Wilm,M., Vorm,O. \& Mann,M. Mass spectrometric sequencing of proteins silver-stained polyacrylamide gels. _Anal. Chem_. ${ }^{\star \star 68}{ }^{\star \star}, 850-858 \backslash(1996)$

\section{Acknowledgements}

This work was supported by the Deutsche Forschungsgemeinschaft grants SFB 571-A1 and the Hermann and Lilly Schilling Foundation. 